\title{
SOX7 is involved in polyphyllin D-induced G0/G1 cell cycle arrest through down-regulation of cyclin D1
}

BIN ZHENG

GANG WANG

WENBO GAO

QIQUAN WU

WEIZHI ZHU

GUOBIN WENG*

Department of Urologic Surgery, Ningbo Yinzhou Second Hospital, Ningbo 315100, China
Accepted June 6, 2019

Published online July 8, 2019

\begin{abstract}
The incidence of mortality of prostate cancer ( $\mathrm{PCa}$ ) has been an uptrend in recent years. Our previous study showed that the sex-determining region Y-box 7 (SOX7) was low-expressed and served as a tumor suppressor in PCa cells. Here, we describe the effects of polyphyllin $\mathrm{D}(\mathrm{PD})$ on proliferation and cell cycle modifications of PCa cells, and whether SOX7 participates in this process. PC-3 cells were cultured in complete medium containing PD for 12, 24, and $48 \mathrm{~h}$. MTT assay was used to investigate the cytotoxic effects of PD. Cell cycle progression was analyzed using propidium iodide (PI) staining, and protein levels were assayed by Western blot analysis. Our results showed low expression of SOX7 in PCa tissues/cells compared to their non-tumorous counterparts/ RWPE-1 cells. Moreover, PD inhibited the proliferation of PC-3 cells in a dose- and time-dependent manner. PD induced G0/G1 cell cycle arrest, while co-treatment with short interfering RNA targeting SOX7 (siSOX7) had reversed this effect. PD downregulated SOX7, cyclin D1, cyclin-dependent kinase 4 (CDK4), and cyclin-dependent kinase 6 (CDK6) expressions in a dose-dependent manner, whereas co-treatment of siSOX7 and PD rescued the PD-inhibited cyclin D1 expression. However, no obvious changes were observed in CDK4 or CDK6 expression. These results indicate that SOX7 is involved in PD-induced PC-3 cell cycle arrest through down-regulation of cyclin D1.
\end{abstract}

Keywords: SOX7, prostate cancer, cell cycle arrest, cyclin D1, polyphyllin D

Prostate cancer (PCa) is a common malignancy. Through 2017, it remained the third leading cause of cancer-related death in male individuals (1). The continuously rising incidence and prominence had made the heterogeneous-multifocal disease difficult to treat (2). Considering the poor prognosis and high mortality of $\mathrm{PCa}$, there is a need for better understanding of the underlying molecular mechanisms in the PCa tumorigenesis to develop better biomarkers for early diagnosis and therapy methods.

\footnotetext{
*Correspondence; e-mail: wgbninbo@126.com
} 
The herb Paris polyphylla is a traditional Chinese drug that has heat-clearing and detoxicating effects. Polyphyllin D (PD) is the major component of Paris polyphylla, and it has been used to treat such ailments as convulsions, mastitis, and tumors of the respiratory system, as well as leukemia $(3,4,5)$. Studies have shown that PD functions as an anti-tumor agent through the inhibition of cell proliferation and by inducing apoptosis in several tumor cell types $(5,6,7)$. However, none of the studies have evaluated the cytotoxicity of $\mathrm{PD}$ against $\mathrm{PCa}$. Our preliminary results have indicated that PD exerts potent cytotoxicity effect against PCa cells in the MTT assay, but the underlying molecular mechanisms of the process have not yet been elucidated.

The transcription factor sex-determining region Y-box 7 (SOX7) is a member of the SRY-related high-mobility group box (SOX) family, located on chromosome 8 (8p22). SOX7, together with SOX17 and SOX18, comprises the SOXF subfamily, which participates in various biological processes, including the regulation of vasculogenesis (8), hematopoiesis (9), cardiogenesis (10), and myogenesis (11). Studies have reported that SOX7 acts as a tumor suppressor in the breast (12), lung (13), colorectal (14), liver (15), and gastric cancers (16). Guo et al. (17) reported that tumor suppressor SOX7 functions as an independent checkpoint for beta-catenin transcriptional activity in PCa Our previous study showed that SOX7 is expressed at low levels and inhibits PC-3 cell proliferation, cell cycle, migration, and invasion (18). However, whether SOX7 participated in the inhibition effect of PD-treated PCa cells remains unknown. This study, therefore, aims to explore the role of SOX7 on cell proliferation and cell cycle changes in PD-treated PCa cells.

\section{EXPERIMENTAL}

\section{Reagents}

PD was purchased from Nanjing Spring\&Autumn Biological Engineering Co., Ltd. (China). The purified PD (>98\%) was dissolved in methanol at $10 \mathrm{mmol} \mathrm{L}^{-1}$ as a stock solution. The working solution was collected in a basal medium with the final methanol concentration of $0.05 \%$. The controls were also treated with an equal amount of methanol as used in the corresponding experiments. The MTT assay kit was purchased from Promega (USA). Propidium iodide (PI) and Cell cycle detection kit were bought from Beyotime Co., Ltd. (China). All chemicals used in this study were reagent grade and commercial products.

\section{Cell culture}

PC-3 and human prostate epithelial cell line RWPE-1 were obtained from Shanghai Institutes for Biological Sciences, Chinese Academy of Sciences (China). PC-3 cells were cultured in an F-12 medium (Gibco, USA), and RWPE-1 cells were cultured in a K-SFM medium (Invitrogen, USA). Both media were supplemented with $10 \%$ inactivated fetal bovine serum (Hyclone, New Zealand), $100 \mathrm{mg} \mathrm{mL}^{-1}$ of penicillin (Hyclone) and $100 \mathrm{U} \mathrm{mL}^{-1}$ of streptomycin (Hyclone). All cells were incubated at $37^{\circ} \mathrm{C}$ in $5 \% \mathrm{CO}_{2}$. 


\section{Cell viability assay}

MTT assay was used to evaluate PC-3 cell viability after treatment with various concentrations of PD (0 (control), 0.01, 0.1, 1.0, or $\left.10.0 \mu \mathrm{mol} \mathrm{L}^{-1}\right)$. Cells were seeded in 96-well plates at a concentration of $1.0 \times 10^{4}$ cells/well, followed by incubation at $37^{\circ} \mathrm{C}$ in $5 \% \mathrm{CO}_{2}$. Subsequent to 0,12, 24 and $48 \mathrm{~h}$ of incubation, $20 \mu \mathrm{L}$ of CellTiter 96 Aqueous One Solution Reagent was added to each well. The absorbance at $492 \mathrm{~nm}$ was measured using a spectrophotometer.

\section{Cell transfection}

Cells were transfected with siSOX7 (GenePharma, China) using lipofectamine ${ }^{\mathrm{TM}}$ 2000 (Invitrogen, USA), according to the manufacturer's protocol. After $24 \mathrm{~h}$ transfection, cells were treated with PD and cultured for another $24 \mathrm{~h}$, prior to collection for further analysis (19).

\section{Western blot}

Cells were harvested and lysed with radioimmunoprecipitation assay (RIPA) buffer (Solarbio, China) containing $1 \%$ protease inhibitor phenylmethanesulfonyl fluoride (PMSF) (Solarbio). Total protein concentrations were measured by bicinchoninic acid (BCA) protein Assay (Beyotime, China). For the Western blot, $30 \mu \mathrm{g}$ of protein from each sample was subjected to $12 \%$ SDS-PAGE, transferred electrophoretically to polyvinylidene difluoride (PVDF) membranes, and subsequently blocked with $5 \%$ non-fat dry milk (blocking buffer). PVDF membranes were incubated overnight at $4{ }^{\circ} \mathrm{C}$ with the following specific primary antibodies: Cyclin D1 (\#2987), CDK4 (\#2906), CDK6 (\#3136), P21 (\#2946), P27 (\#2552), and GAPDH (\#5174) (CST, USA, dilution 1:800), and SOX7 (ab89954) (Abcam, UK, dilution 1:800). Horseradish peroxidase (HRP) labeled secondary antibody including goat anti-mouse IgG-HRP (BA1051) or goat anti-rabbit IgG-HRP (BA1055) (Boster, China, dilution 1:5,000) was incubated for $2 \mathrm{~h}$ at room temperature. Specific antibody binding was visualized using enhanced chemiluminescence reagent (20). Tanon GIS software (Tanon, China) was used to calculate the band intensity of each protein.

\section{Cell cycle assay}

To determine the distribution of cell cycle stages, cells were washed with phosphate buffer saline (PBS) and fixed with chilled $100 \%$ ethanol for $24 \mathrm{~h}$. The fixed cells were stained with PI, and flow cytometric analysis was then performed by a FACSCalibur flow cytometer (Becton Dickinson, USA). Data were analyzed using the MODFIT software (USA) (21).

\section{Tissue samples}

Pair-matched PCa and their adjacent non-tumor tissues were obtained from the pathology department of Ningbo Yinzhou Second Hospital. The informed consent was obtained by each patient and study protocol was approved by Ethical Committee of Ningbo Yinzhou Second Hospital. 


\section{Statistical analysis}

All data were shown as means \pm standard deviation (SD) of three independent experiments. Groups were statistically compared by one-way analysis of variance with Dunnett's test or unpaired Student's $t$-test. $p<0.05$ was considered statistically significant.

\section{RESULTS AND DISCUSSION}

Current PCa therapies have limited effectiveness and safeness in the clinic due to intolerable side-effects present in most cases (2). During the past several years, the overall survival rate of PCa remained stagnant even in patients treated with combined chemotherapy and radiotherapy. In addition, the systemic toxicity of the chemotherapeutic agents, which patients cannot easily tolerate, has limited their application in the clinic (22). Therefore, the search for novel therapeutic drugs with improved clinical efficacy and safety for PCa treatment is highly desired.a

a)

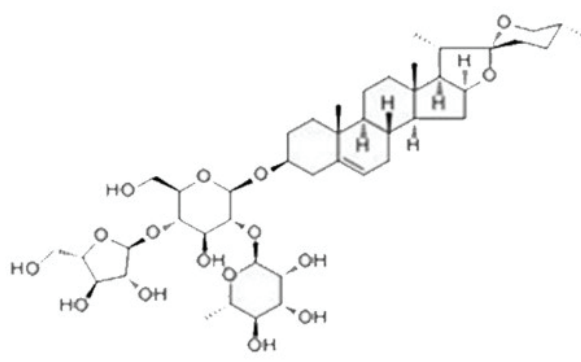

b)

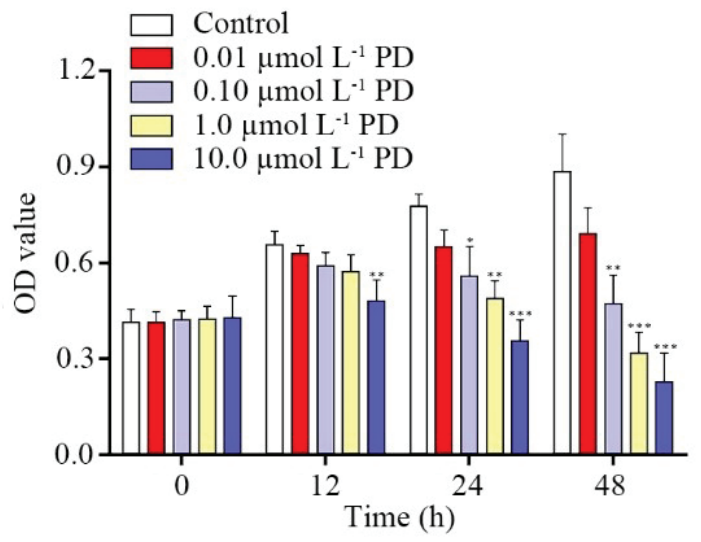

Fig. 1. Effect of polyphyllin D (PD) on PC-3 cell viability. a) Chemical structure of PD; b) PC-3 cells were treated with specific concentrations of PD ( 0 (control), $\left.0.01,0.10,1.0,10 \mu \mathrm{mol} \mathrm{L}^{-1}\right)$ for $0,12,24$, and $48 \mathrm{~h}$; Cell viability was measured using MTT assay. ${ }^{*} p<0.05,{ }^{* *} p<0.01,{ }^{* * *} p<0.001$ vs. the control cells (without PD treatment). 
a)
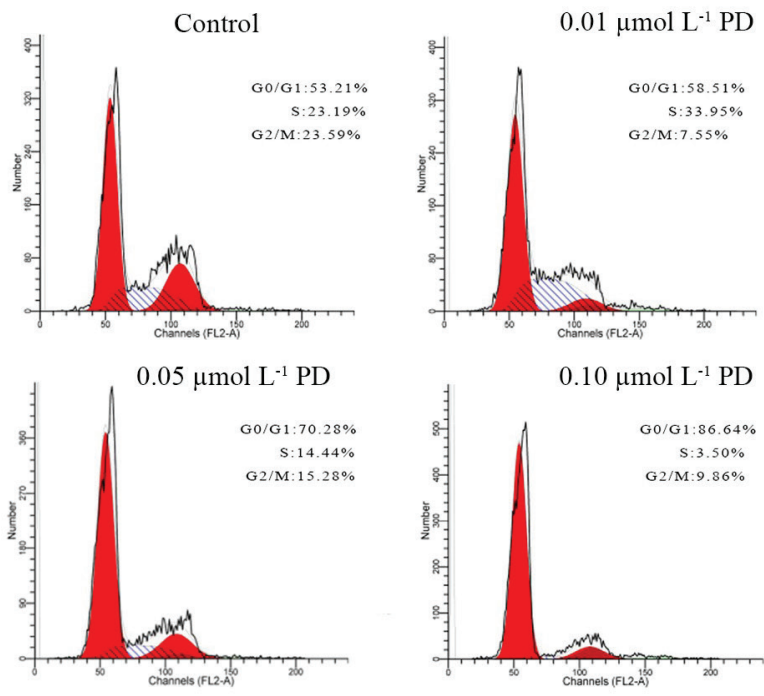

b)

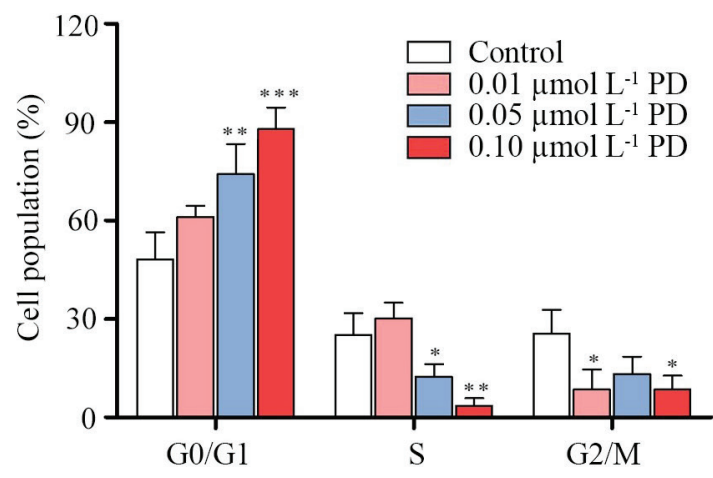

Fig. 2. Effect of PD on PC-3 cell cycle distribution. PC-3 cells were treated without or with $0.01,0.05$ and $0.10 \mu \mathrm{mol} \mathrm{L}^{-1} \mathrm{PD}$ for $24 \mathrm{~h}$. a) Distributions of cell cycle were analyzed by flow cytometry; b) Bars display the percentage distribution of cells across the cell cycle; Data are presented as mean $\pm \mathrm{SD}, n$ $=3 .{ }^{*} p<0.05,{ }^{* *} p<0.01,{ }^{* * *} p<0.001$ vs. the control cells.

Natural products and their extracts are being studied as new and promising resources for anti-PCa drugs. Recently, PD (Fig. 1a) has attracted a great deal of attention due to its ability to directly trigger mitochondrial membrane permeabilization and to induce apoptosis (23). However, to our knowledge, little has been determined about its effect on PC-3 cells. Here, we examined PD-treated PC-3 cells and found that PD substantially inhibited the cell viability of PC-3 cells in a time- and concentration-dependent manner (Fig. 1b).

Cyclins participate in the control of the cell cycle progression by activating CDKs (24, 25). During the G1 phase, cyclin D1 forms a complex with CDK4 or CDK6 and promotes 
a)

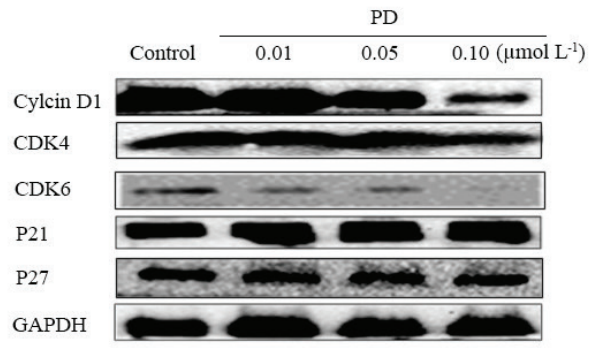

b)

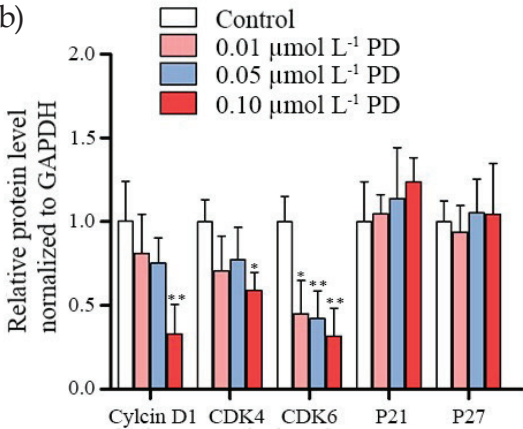

Fig. 3. Effect of PD on the expression of G0/G1 cell cycle related proteins. PC-3 cells were treated without or with $0.01,0.05$, and $0.10 \mu \mathrm{mol} \mathrm{L}^{-1} \mathrm{PD}$ for $24 \mathrm{~h}$. Cyclin D1, cyclin-dependent kinase 4 (CDK4), cyclin-dependent kinase 6 (CDK6), cyclin-dependent kinase inhibitor 1A (P21) and cyclin-dependent kinase inhibitor 1B (P27) were assayed by Western blot. GAPDH was used as an internal reference. a) Representative immunoblotting bands; b) Analysis of band intensities of cyclin D1, CDK4, CDK6, P21, and P27 are presented. Data are presented as the mean $\pm \mathrm{SD}, n=3 ;{ }^{*} p<0.05,{ }^{* *} p<0.01$ vs. the control cells.

the cell cycle progression from G0/G1 phase to S phase (26). However, cyclin-dependent kinase inhibitors (CDKIs) can especially recognize and bind with the cyclins/CDKs complex, thus inhibiting their activities and regulating the cell cycle progression. The G1-S transition could be regulated by CDKIs, such as P21 and P27, through inhibition of cyclins/ CDKs activities (27). Therefore, direct or indirect regulation of cyclins through up-regulation of CDKIs is a potential approach to determine the cell cycle progression. In the present study, we found that the treatment with PD had caused G0/G1 phase arrest and decreased the expressions of cyclin D1, CDK4, and CDK6, while no significant changes in P21 and P27 levels were observed (Fig. 2 and Fig. 3). However, it remains unknown which of the downstream nuclear effectors participate in the process of PD-reduced cyclin D1/CDKs complexes activities.

Emerging evidence has suggested that SOX7 is downregulated in various types of cancer tissues relative to their non-tumorous counterparts $(19,28-30)$. Our results also

a)

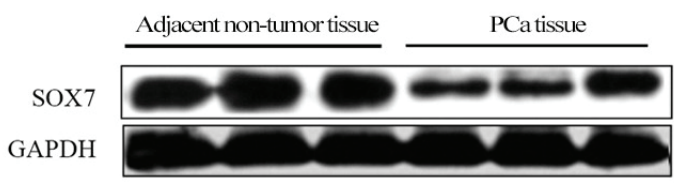

b)

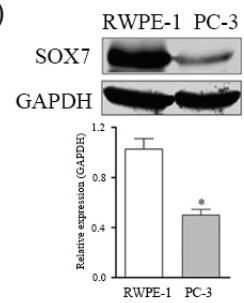

Fig. 4. Sex-determining region Y-box 7 (SOX7) is low-expressed in PCa tissues and cells. a) Western blot was performed to detect the expressions of SOX7 in PCa and adjacent non-tumor tissues, and b) in PC-3 and RWPE- 1 cells. Analysis of band intensity of SOX7 in PC-3 and RWPE-1 cells is also shown. ${ }^{*} p<0.05$, vs. the RWPE-1 cells. 
a)

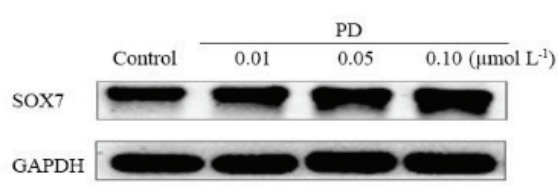

b)

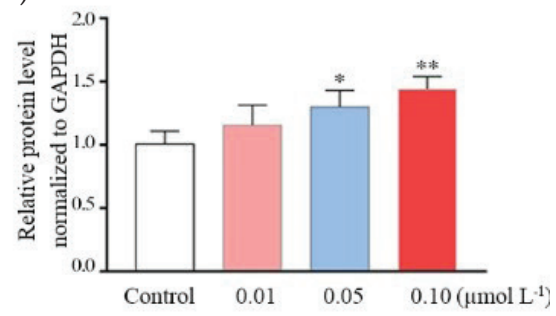

Fig. 5. Effect of PD on SOX7 expression. PC-3 cells were treated without or with 0.01, 0.05, and 0.10 $\mu \mathrm{mol} \mathrm{L}{ }^{-1} \mathrm{PD}$ for $24 \mathrm{~h}$. a) Representative immunoblotting bands; b) Analysis of band intensity. Results represent mean $\pm \mathrm{SD}, \mathrm{n}=3 .{ }^{*} p<0.05,{ }^{* *} p<0.05 v$ s. the control cells.

a)

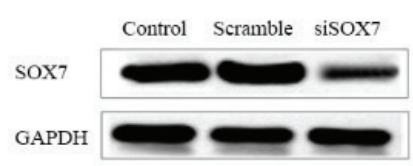

c)
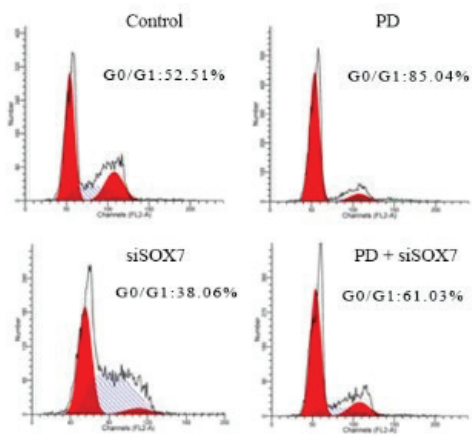

e)

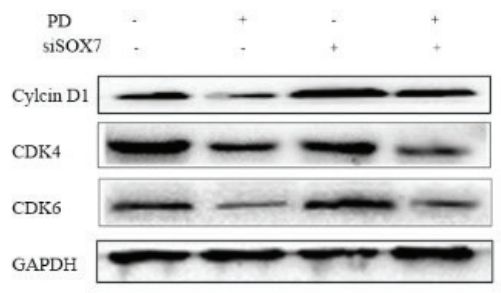

b)

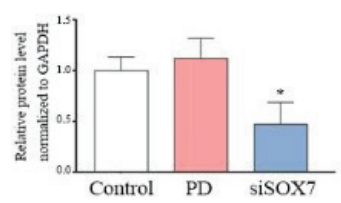

d)

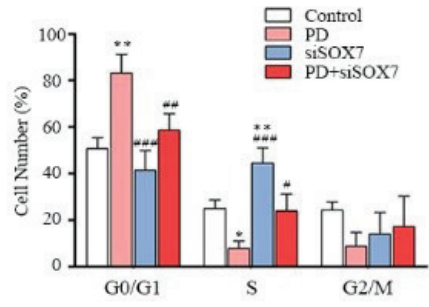

f)

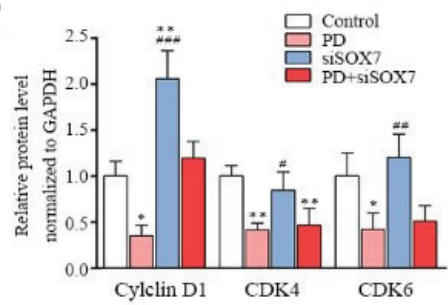

Fig. 6. PD-induced cell cycle arrest was mediated by transcription factor SOX7. a) and b) After PC-3 cells were transfected with short interfering RNA targeting SOX7 (siSOX7) for $24 \mathrm{~h}$, expressions of SOX7 were assayed by Western blot; c) and d) Cell cycle distribution measured by a flow cytometer; e) and f) The expression levels of cyclin D1, CDK4 and CDK6 assayed by Western blot. All data were presented as means $\pm \mathrm{SD}, n=3 .{ }^{*} p<0.05,{ }^{* *} p<0.01$ vs. the control cells. ${ }^{\sharp} p<0.05,{ }^{\sharp \#} p<0.01,{ }^{\# \# \#} p<0.001$ vs. the PD-treated cells. 
showed SOX7 to be expressed at lower levels in PCa tissues than in adjacent non-tumor tissue (Fig. 4), indicating that SOX7 acts as a tumor suppressor in PCa progression. In addition, Wang et al. (31) showed that ectopic-expression of SOX7 reduced cell proliferation in renal cancer cells, whereas knockdown of SOX7 promoted it. Chan et al. (32) reported SOX7 to be a negative upstream regulator of the Wnt targets, including cyclin D1 and cmyc, in endometrial cancer cells. Similar results were also observed in ovarian, colorectal, and liver cancer cells $(30,33)$. Cyclin D1 acts as a growth sensor and provides a link between mitogenic stimuli and the cell cycle (34). SOX7 could control G1/S progression by regulating cyclin D1 and c-myc, but has no marked influence on CDK4 and CDK6 expression levels in liver cancer cells $(35,36)$.

Here, we addressed whether SOX7 is involved in PD-induced G0/G1 cell cycle arrest in PCa cells. Our results showed that PD was capable of rising SOX7 levels in a dose-dependent manner (Fig. 5). To confirm the role of SOX7 in PD-induced changes in the cell cycle, we transfected cells with siSOX7 to silence the SOX7 levels (Fig. 6a and b). Flow cytometer data showed that PD markedly increased the number of cells in the G0/G1 phase, while co-treatment of siSOX7 and PD reversed PD-induced G0/G1 cell cycle arrest (Fig. 6c and d). Moreover, the addition of siSOX7 also rescued PD-inhibited cyclin D1 expression, while no obvious changes were observed in PD-inhibited CDK4 and CDK6 (Fig. 6e and f). These results suggest that cyclin D1, but not CDK4 and CDK6, is regulated by SOX7 in PCa cells, which is consistent with previous studies researched in liver cancer (35). Taken together, these data indicate that SOX7-mediated PD-induced cell cycle arrest in the G0/G1 phase is associated with changes in cyclin D1 expressions.

\section{CONCLUSIONS}

These results demonstrate that SOX7 is involved in PD-induced G0/G1 cell cycle arrest by downregulation of cyclin D1 expression. However, further research is needed to fully characterize the biological functions of SOX7 and its clinical relevance in the development of PCa. Collectively, SOX7 may be a potential therapeutic target by PD, and further indepth studies are needed to focus on the safety of PD in PCa therapies.

Acknowledgments. - We appreciate the support of the Foundation of Ningbo Science and Technology Benefiting People Project (2017C50058) and Science and Technology Project of Yinzhou District.

\section{REFERENCES}

1. R. L. Siegel, K. D. Miller and A. Jemal, Cancer Statistics, 2017, CA Cancer J. Clin. 67 (2017) 7-30; https://doi.org/10.3322/caac.21387

2. L. G. Gomella, Prostate cancer statistics: anything you want them to be, Can. J. Urol. 24 (2017) 8603-8604; https://www.canjurol.com/html/free-articles/V24I1_03_FREE_Editorial_Feb17.pdf

3. S. Watanabe, T. Suzuki, F. Hara, T. Yasui, N. Uga and A. Naoe, Poly phyllin D, a steroidal saponin in Paris polyphylla, induces apoptosis and necroptosis cell death of neuroblastoma cells, Pediatr. Surg. Int. 33 (2017) 713-719; https://doi.org/10.1007/s00383-017-4069-4

4. D. D. Ma, H. X. Lu, L. S. Xu and W. Xiao, Polyphyllin D exerts potent anti-tumour effects on Lewis cancer cells under hypoxic conditions, J. Int. Med. Res. 37 (2009) 631-640; https://doi. org/10.1177/147323000903700305 
5. C. Yang, H. Cai and X. Meng, Polyphyllin D induces apoptosis and differentiation in K562 human leukemia cells, Int. Immunopharmacol. 36 (2016) 17-22; https://doi.org/10.1016/j.intimp.2016.04.011

6. E. Al Sawah, D. C. Marchion, Y. Xiong, I. J. Ramirez, F. Abbasi, B. M. Boac, S. H. Bush, N. Bou Zgheib, E. C. McClung, B. R. Khulpateea, A. Berry, A. Hakam, R. M. Wenham, J. M. Lancaster and P. L. Judson, The Chinese herb polyphyllin D sensitizes ovarian cancer cells to cisplatin-induced growth arrest, J. Cancer Res. Clin. Oncol. 141 (2015) 237-242; https://doi.org/10.1007/s00432-014-1797-x

7. L. Wu, Q. Li and Y. Liu, Polyphyllin D induces apoptosis in K562/A02 cells through G2/M phase arrest, J. Pharm. Pharmacol. 66 (2014) 713-721; https://doi.org/10.1111/jphp.12188

8. M. Francois, P. Koopman and M. Beltrame, SoxF genes: Key players in the development of the cardio-vascular system, Int. J. Biochem. Cell Biol. 42 (2010) 445-448; https://doi.org/10.1016/j.biocel.2009.08.017

9. A. Gandillet, A. G. Serrano, S. Pearson, A. L. M. Lie, G. Lacaud and V. Kouskoff, SOX7-sustained expression alters the balance between proliferation and differentiation of hematopoietic progenitors at the onset of blood specification, Blood 114 (2009) 4813-4822; https://doi.org/10.1182/ blood-2009-06-226290

10. T. J. Nelson, A. Chiriac, R. S. Faustino, R. J. Crespo-Diaz, A. Behfar and A. Terzic, Lineage specification of Flk-1+ progenitors is associated with divergent SOX7 expression in cardiopoiesis, Differentiation 77 (2009) 248-255; https://doi.org/10.1016/j.diff.2008.10.012

11. J. Savage, A. J. Conley, A. Blais and I. S. Skerjanc, SOX15 and SOX7 differentially regulate the myogenic program in P19 cells, Stem Cells 27 (2009) 1231-1243; https://doi.org/10.1002/stem.57

12. F. Shen, W. S. Cai, Z. Feng, J. L. Li, J. W. Chen, J. Cao and B. Xu, MiR-492 contributes to cell proliferation and cell cycle of human breast cancer cells by suppressing SOX7 expression, Tumour Biol. 36 (2015) 1913-1921; https://doi.org/10.1007/s13277-014-2794-Z

13. P. Wang, D. Chen, H. Ma and Y. Li, LncRNA MEG3 enhances cisplatin sensitivity in non-small cell lung cancer by regulating miR-21-5p/SOX7 axis, Oncol. Targets Ther. 10 (2017) 5137-5149; https:// doi.org/10.2147/OTT.S146423

14. Y. Wang, C. Du, N. Zhang, M. Li, Y. Liu, M. Zhao, F. Wang and F. Luo, TGF-beta1 mediates the effects of aspirin on colonic tumor cell proliferation and apoptosis, Oncol. Lett. 15 (2018) 5903-5909; https://doi.org/10.3892/ol.2018.8047

15. J. Wang, S. Zhang, J. Wu, Z. Lu, J. Yang, H. Wu, H. Chen, B. Lin and T. Cao, Clinical significance and prognostic value of SOX7 expression in liver and pancreatic carcinoma, Mol. Med. Rep. 16 (2017) 499-506; https://doi.org/10.3892/mmr.2017.6660

16. M. Yang, G. Cui, M. Ding, W. Yang, Y. Liu, D. Dai and L. Chen, miR-935 promotes gastric cancer cell proliferation by targeting SOX7, Biomed. Pharmacother. 79 (2016) 153-158; https://doi. org/10.1016/j.biopha.2016.01.011

17. L. Guo, D. Zhong, S. Lau, X. Liu, X. Y. Dong, X. Sun, V. W. Yang, P. M. Vertino, C. S. Moreno, V. Varma, J. T. Dong and W. Zhou, Sox7 Is an independent checkpoint for beta-catenin function in prostate and colon epithelial cells, Mol. Cancer Res. 6 (2008) 1421-1430; https://doi.org/10.1158/15417786.MCR-07-2175

18. B. Zheng, Q. Wu, K. Zhou, Gang. W. Y. Ren, H. Qi, W. Zhu and G. Weng, Mechanisms and effects of transcription factor SOX7 on the biological activity of the prostate cancer PC-3 cells, J. Wenzhou Medical University. 47 (2017) 678-682; https://doi.org/10.3969/j.issn.2095-9400.2017.09.011

19. C. Xiuju, W. Zhen and S. Yanchao, SOX7 inhibits tumor progression of glioblastoma and is regulated by miRNA-24, Open Med. (Wars). 11 (2016) 133-137; https://doi.org/10.1515/med-2016-0026

20. S. Huang, P. Cui, S. Lin, X. Yao, X. Wang, Y. Ren and G. Weng, The transcription factor creb is involved in sorafenib-inhibited renal cancer cell proliferation, migration and invasion, Acta Pharm. 68 (2018) 497-506; https://doi.org/10.2478/acph-2018-0033

21. W. Liu, R. Ning, R. N. Chen, X. F. Huang, Q. S. Dai, J. H. Hu, Y. W. Wang, L. L. Wu, J. Xiong, G. Hu, Q. L. Guo, J. Yang and H. Wang, Aspafilioside B induces G2/M cell cycle arrest and apoptosis by up-regulating H-Ras and N-Ras via ERK and p38 MAPK signaling pathways in human hepatoma HepG2 cells, Mol. Carcinog. 55 (2016) 440-457; https://doi.org/10.1002/mc.22293 
22. M. E. O'Callaghan, E. Raymond, J. Campbell, A. D. Vincent, K. Beckmann, D. Roder, S. Evans, J. McNeil, J. Millar, J. Zalcberg, M. Borg and K. Moretti, Tools for predicting patient-reported outcomes in prostate cancer patients undergoing radical prostatectomy: a systematic review of prognostic accuracy and validity, Prostate Cancer Prostatic Dis. 20 (2017) 378-388; https://doi.org/10.1038/ pcan. 2017.28

23. R. C. Ong, J. Lei, R. K. Lee, J. Y. Cheung, K. P. Fung, C. Lin, H. P. Ho, B. Yu, M. Li and S. K. Kong, Polyphyllin D induces mitochondrial fragmentation and acts directly on the mitochondria to induce apoptosis in drug-resistant HepG2 cells, Cancer Lett. 261 (2008) 158-164; https://doi. org/10.1016/j.canlet.2007.11.005

24. Y. Luo, J. Hurwitz and J. Massague, Cell-cycle inhibition by independent CDK and PCNA binding domains in p21Cip1, Nature 375 (1995) 159-161; https://doi.org/10.1038/375159a0

25. M. P. Swaffer, A. W. Jones, H. R. Flynn, A. P. Snijders and P. Nurse, CDK Substrate Phosphorylation and Ordering the Cell Cycle, Cell. 167 (2016) 1750-1761 e1716; https://doi.org/10.1016/j.cell.2016.11.034

26. U. Galderisi, F. P. Jori and A. Giordano, Cell cycle regulation and neural differentiation, Oncogene 22 (2003) 5208-5219; https://doi.org/10.1038/sj.onc.1206558

27. D. Ye, H. Luo, Z. Lai, L. Zou, L. Zhu, J. Mao, T. Jacob, W. Ye, L. Wang and L. Chen, ClC-3 Chloride Channel Proteins Regulate the Cell Cycle by Up-regulating cyclin D1-CDK4/6 through Suppressing p21/p27 Expression in Nasopharyngeal Carcinoma Cells, Sci. Rep. 6 (2016) 30276; https://doi. org/10.1038/srep30276

28. H. Liu, E. Mastriani, Z. Q. Yan, S. Y. Yin, Z. Zeng, H. Wang, Q. H. Li, H. Y. Liu, X. Wang, H. X. Bao, Y. J. Zhou, J. J. Kou, D. Li, T. Li, J. Liu, Y. Liu, L. Yin, L. Qiu, L. Gong and S. L. Liu, SOX7 co-regulates Wnt/beta-catenin signaling with Axin-2: both expressed at low levels in breast cancer, Sci. Rep. 6 (2016) 26136; https://doi.org/10.1038/srep26136

29. D. Chen, J. Li, S. Li, P. Han, N. Li, Y. Wang and S. Du, miR-184 promotes cell proliferation in tongue squamous cell carcinoma by targeting SOX7, Oncol. Lett. 16 (2018) 2221-2228; https://doi.org/10.3892/ ol.2018.8906

30. H. Liu, Z. Q. Yan, B. Li, S. Y. Yin, Q. Sun, J. J. Kou, D. Ye, K. Ferns, H. Y. Liu and S. L. Liu, Reduced expression of SOX7 in ovarian cancer: a novel tumor suppressor through the Wnt/beta-catenin signaling pathway, J, Ovarian Res. 7 (2014) 87; https://doi.org/10.1186/s13048-014-0087-1

31. L. Wang, Y. Fan, L. Zhang, L. Li, G. Kuang, C. Luo, C. Li, T. Xiang, Q. Tao, Q. Zhang and J. Ying, Classic SRY-box protein SOX7 functions as a tumor suppressor regulating WNT signaling and is methylated in renal cell carcinoma, FASEB J. 33 (2019) 254-263; https://doi.org/10.1096/ fj.201701453RR

32. D. W. Chan, C. S. Mak, T. H. Leung, K. K. Chan and H. Y. Ngan, Down-regulation of Sox7 is associated with aberrant activation of $\mathrm{Wnt} / \mathrm{b}$-catenin signaling in endometrial cancer, Oncotarget. 3 (2012) 1546-1556; https://doi.org/10.18632/oncotarget.667

33. X. Zhou, S. Y. Huang, J. X. Feng, Y. Y. Gao, L. Zhao, J. Lu, B. Q. Huang and Y. Zhang, SOX7 is involved in aspirin-mediated growth inhibition of human colorectal cancer cells, World J. Gastroenterol. 17 (2011) 4922-4927; https://doi.org/10.3748/wjg.v17.i44.4922

34. K. Vermeulen, D. R. V. Bockstaele and Z. N. Berneman, The cell cycle: a review of regulation, deregulation and therapeutic targets in cancer, Cell Proliferation 36 (2003) 131-149; http://dx.doi. org/10.1046/j.1365-2184.2003.00266.x

35. C. Wang, Y. Guo, J. Wang and Z. Min, The suppressive role of SOX7 in hepatocarcinogenesis, PLoS One. 9 (2014) e97433; https://doi.org/10.1371/journal.pone.0097433

36. X. Liu, J. Li, Z. Yu, J. Li, R. Sun and Q. Kan, miR-935 promotes liver cancer cell proliferation and migration by targeting SOX7, Oncol. Res. 25 (2017) 427-435; https://doi.org/10.3727/09650401 6X14747300207374 